\title{
Gastrointestinal malignancies at five regional referral hospitals in Uganda.
}

\author{
Siraji Obayo ${ }^{1}$, Luswa Lukwago $^{2}$, Jackson Orem $^{3}$, Ashley L Faulx ${ }^{4}$, Christopher S Probert $^{5}$
}

1. Mbarara University Teaching Hospital, Mbarara, Uganda and the Uganda Cancer Institute, Kampala, Uganda.

2. Ministry of Health Department of Epidemiology, Kampala Uganda.

3. The Uganda Cancer Institute, Kampala, Uganda

4. University Hospitals Cleveland Medical Center, Ohio, USA.

6. Institute of Translational Medicine, University of Liverpool United Kingdom.

\begin{abstract}
:
Background: There is a paucity of published data regarding the trend and distribution of gastrointestinal malignancies in Uganda.

Objectives: To study the trend and distribution of gastrointestinal malignancies over a 10 year period at five regional referral hospitals in Uganda.

Methods: Patient's charts with histologically confirmed diagnoses of gastrointestinal malignancies for the period 2002-2011 were identified. Case information, which included age at diagnosis, sex, and year of diagnosis, primary anatomic site of the tumour and hospitals attended, was retrospectively abstracted. Patient's clinical and demographic features were compared.

Results: Oesophageal cancer was the most common (28.8\%) followed by liver (25.8\%), stomach (18.4\%) and colorectal (14.3\%). The mean age at diagnosis for all the cancers was not significantly different in both sexes 54.1, (SD16.1) versus 53.6, (SD 14.7). The highest mean annual number of cases of oesophageal and stomach cancers was 21.8, (SD 15.5) and 16.6, (SD 13.0) respectively from Mbarara Hospital; Lacor had the highest mean annual number of liver cancer cases (21, SD 17.7) followed by Mbale (11.4,SD 8.3). The mean annual number of colorectal cancers was highest in Mbale Hospital (10.3, SD 8.1) followed by Lacor (4.9, SD 3.9). The distribution of oesophageal, liver, stomach and colorectal cancers diagnosed per year across the five referral hospitals was different, $\mathrm{P}<0.001$.

Conclusion: Oesophageal, liver, stomach and colorectal cancer remain the most common gastrointestinal malignancies and their rate is increasing in Uganda. There is a need for awareness, endoscopic and radiological assessment of symptomatic individuals and a need for screening of high index patients.
\end{abstract}

Keywords: Gastrointestinal malignancies, Uganda Regional Referral Hospitals, 10-year trend.

DOI: https://dx.doi.org/10.4314/ahs.v17i4.13

Cite as: Obayo S, Lukwago L, Orem J, Faulx AL, Probert CS. Gastrointestinal malignancies at five regional referral hospitals in Uganda. Afri Health Sci.2017;17(4): 1051-1058. https:// dx.doi.org/10.4314/ahs.v17it.13

\section{Introduction}

Accurate national representative data on the trend and

\section{Corresponding author:}

Siraji Obayo,

Mbarara University Teaching

Hospital and Uganda Cancer Institute,

Upper Mulago Road,

P.O.BOX 3935, Kampala, Uganda.

Telephone: $+256772581873 /+256701581873$.

Email: obayos@yahoo.com distribution of gastrointestinal malignancies in Uganda is sparse, hampering efforts to develop robust public and clinical health interventions. ${ }^{1,2}$ The challenges of diagnosis of these malignancies in this resource limited settings is significant because of inadequate endoscopic, radiological facilities and lack of screening programs. ${ }^{3-5}$ Recent reports from the Kampala Cancer Registry based in Kyadondo County, which represents about $8 \%$ of the Ugandan population, suggest that the trend of gastrointestinal malignancy, specifically oesophageal, stomach, liver and colorectal cancers, is increasing. ${ }^{6}$ However, 90\% of the Ugandan population lives in rural areas: they can 
only access regional referral and district hospitals for their assessment and diagnosis; there is no published data about gastrointestinal cancer cases in these regional referral hospitals. An earlier survey showed variation by geographic location in the distribution of gastrointestinal malignancies, especially for oesophageal and stomach cancer. $^{7}$ Oesophageal cancer was most common around the NorthEast shores of Lake Victoria and rare in Northern and SouthWestern Uganda, while stomach cancer was common in SouthWestern Uganda, but rare in Northern Uganda. Liver cancer was the most frequent cancer in the NorthEast, Northern and SouthWestern Uganda. ${ }^{7}$ Later surveys also found high prevalence of stomach cancer in SouthWestern Uganda. ${ }^{8,9}$ Cancer of the large bowel had long been noted to be relatively infrequent in Uganda, ${ }^{9,10}$ Data from Kyadondo County shows an increasing trend in the incidence of colorectal cancer. ${ }^{11}$

Attempts to determine the pattern of cancer in Mbarara, SouthWestern Uganda, stomach cancer accounted for $12 \%$ of all cancers in males and six percent in females. ${ }^{12}$ The pattern was different from that of Kyadondo County in Central Uganda were stomach cancer was found to be rare, whereas oesophageal was one of the commonest cancer in Kyadondo County but rare in Mbarara. ${ }^{12}$ The pattern of cancer in general and gastrointestinal malignancy in particular is important. National representative data pertaining the pattern and distribution of gastrointestinal malignancies are urgently needed to inform policymakers and support public health messages about cancer to the population where the conditions are most common. Therefore, this retrospective hospital based survey of patients diagnosed with gastrointestinal cancers at five regional-representative hospitals in Uganda was undertaken in order to test the feasibility of obtaining such data from that routinely collected.

\section{Methods}

This was a retrospective study of patients with histological diagnoses of gastrointestinal cancers seen at five referral hospitals in the ten years from January 2002 to December 2011.

The hospitals were: Mbarara University Teaching Hospital, a 600-bed hospital, one of the three national referral hospitals that serves major part of Western Uganda; St. Mary's Hospital Lacor Gulu, a 483-bed hospital that serves major part of Northern Uganda; Mbale Regional
Referral Hospital, a 400-bed hospital and teaching hospital for Busitema University Medical School that serves a population of East and NorthEastern Uganda; Jinja Regional Referral Hospital, a 432-bed hospital in SouthEastern Uganda and a regional referral for Jinja and its neighbouring districts and Soroti Regional Referral Hospital, a 247-bed hospital in NorthEastern Uganda, serving Teso sub-region and its neighbouring districts (Figure 1).The details of patients were retrieved from patients' charts kept in the medical record departments, the surgical wards, operating theaters and histopathology laboratories.

Research assistants compiled case information, including age at diagnosis, sex, and year of diagnosis, primary anatomic site of the tumour, histopathology, and hospital attended using hospital chart abstraction. The information was entered into an epidemiological database for analysis. Analysis was restricted to cases involving the gastrointestinal tract and the study included only regional referral and teaching hospitals where histopathology data would be accessed, thus cases only seen at district hospitals may have been missed and so the completeness of the case series for the regions is uncertain.

The subjects of this study included all patients with histologically confirmed gastrointestinal cancers from the five Referral Hospitals during the period studied. Patients with incomplete data were excluded from the study. The diagnosis of gastrointestinal cancers was performed by endoscopy, double contrast barium meal and laparotomy, and confirmed pathologically by endoscopic and laparotomy biopsies.

\section{Ethical consideration}

We sought permission from individual hospitals prior to accessing charts for data abstraction. The data review was performed as part of cancer survey in collaboration with the Ugandan Ministry of Health with key data collected in aggregate without retaining personal identifying information.

\section{Statistics}

Descriptive analyses of cancers and gender, cases across age groups by gender, cancers across the hospitals, trend and distribution of the cancers with the calendar year were performed in all subjects. The means and their standard deviation of all cancers across the hospitals were calculated. The means were compared across all the five 
hospitals and $\mathrm{p}$ values were computed using a Kruskal Wallis test of means, a p-value of $<0.05$ was considered significant using Stata version 12.0

\section{Results}

1468 cases were identified. The average age at diagnosis was 53.9 years (SD 15.6) with a range of $10-98$ years and the mean age at diagnosis was not significantly different between males and females (54.1 years (SD 16.1) and 53.6 years (SD14.7) respectively, $\mathrm{p}=\mathrm{ns}$ ). Oesophageal cancer was the most common $(28.8 \%)$ followed by liver $(25.8 \%)$,stomach $(18.4 \%)$ and then colorectal cancer $(14.3 \%$ ), all of which were more common in males (Table 1).

Table 1: Anatomical distribution of gastrointestinal cancers reported in 5 hospitals in Uganda between 2002-2011

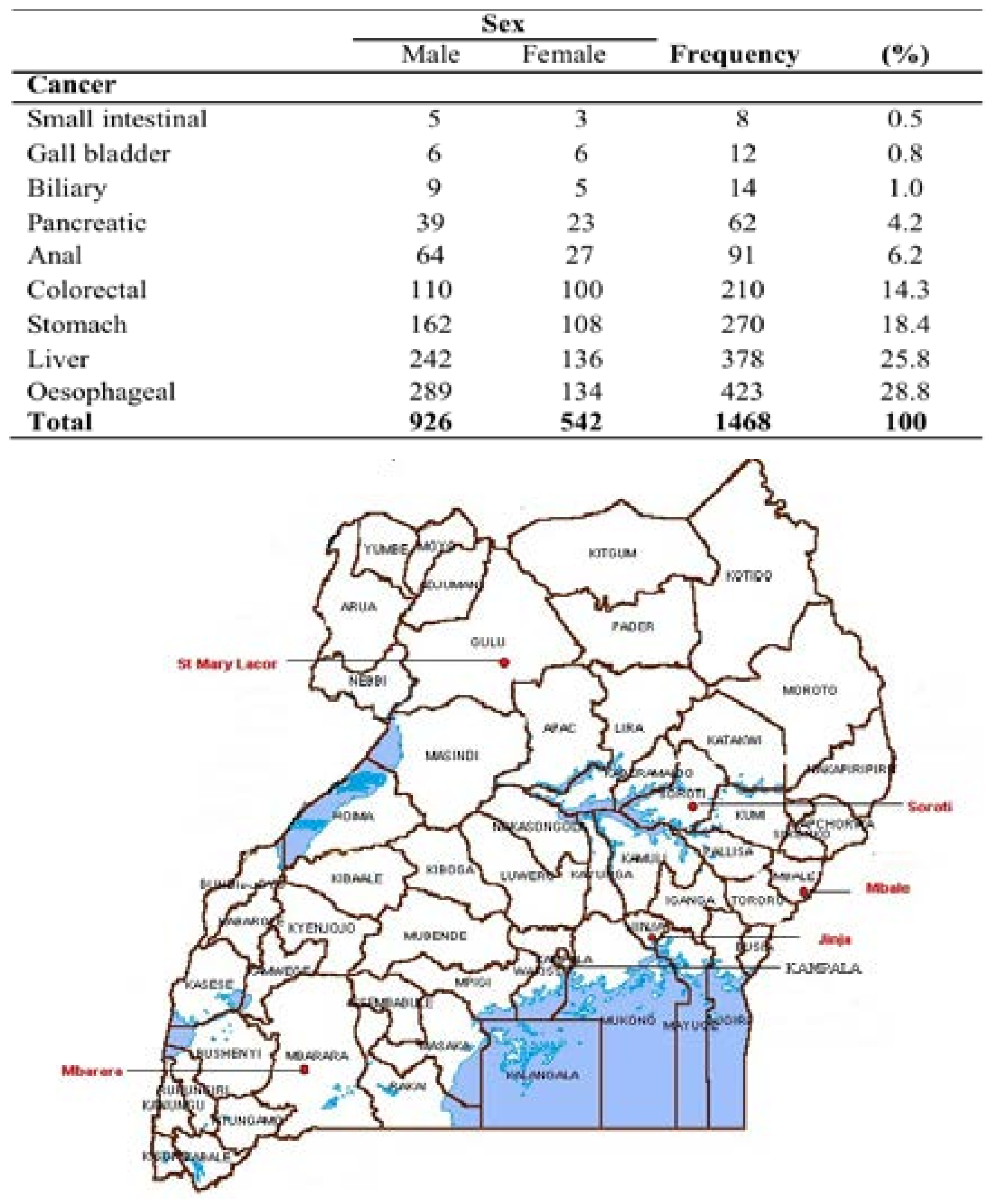

Figure 1: Map showing location of hospitals conducting research 
There were significantly more cancers in men than women across all age groups. Most cancers occurred in those aged 41-60. The trend and distribution of gastrointestinal malignancies generally increased during the 10 -year period with a positive correlation (Figure 2).

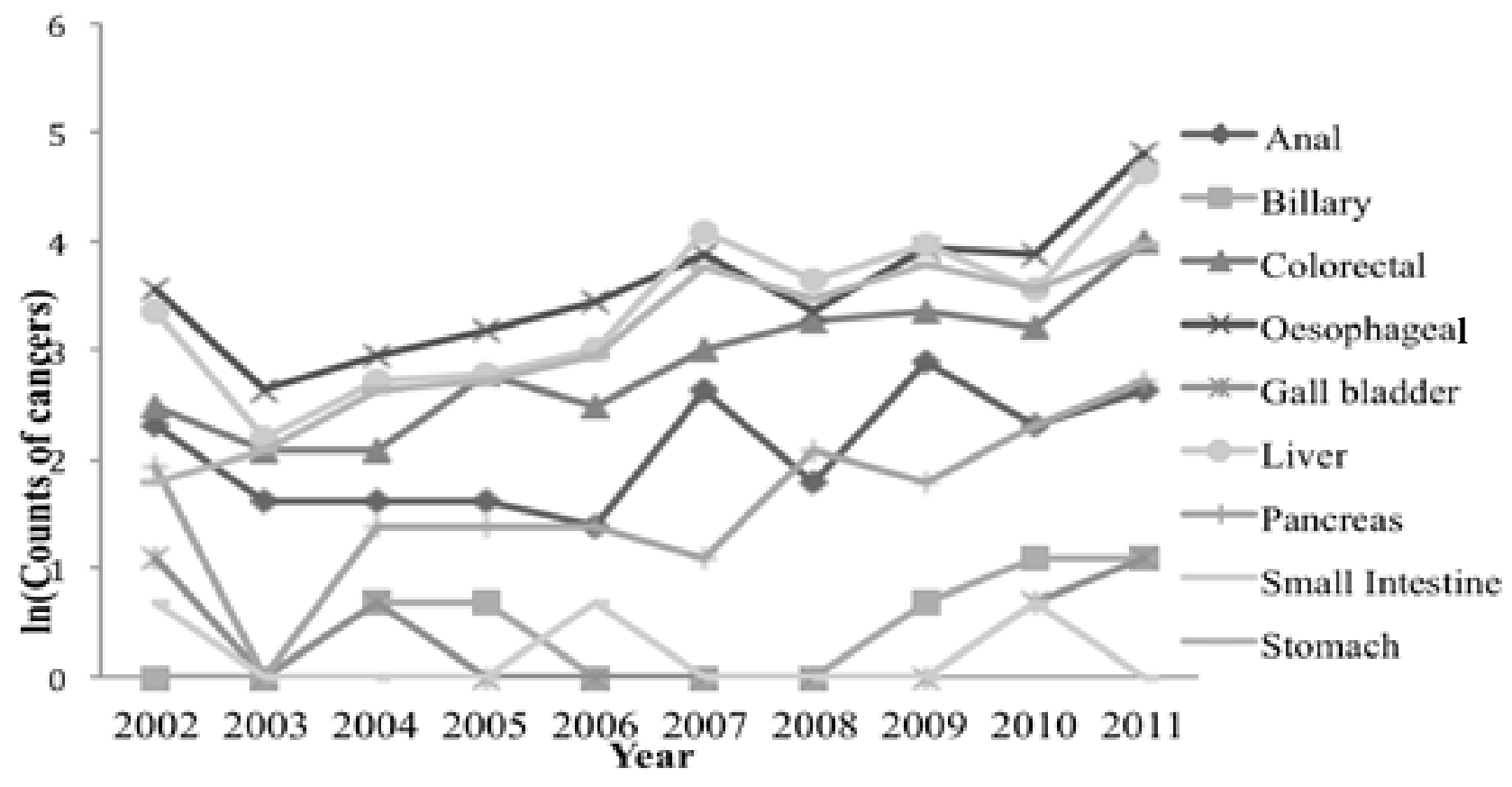

$\begin{array}{llccccc}\text { Cancer } & \text { Anal } & \text { Colorectal } & \text { Oesophageal } & \text { Liver } & \text { Pancreas } & \text { Stomach } \\ \text { Correlation } & 0.562 & 0.890 & 0.742 & 0.769 & 0.632 & 0.939 \\ \text { P-value } & 0.091 & 0.001 & 0.014 & 0.009 & 0.050 & 0.000\end{array}$

Figure 2: The number of gastrointestinal cancer cases with the calendar year.

Mbarara University Teaching Hospital had the highest mean annual number of cases of oesophageal (22, SD 15.5) and stomach cancers (17, SD 13.0) followed by Lacor. St. Mary's Hospital Lacor had the highest mean annual number of cases of liver cancer (21, SD 17.7) fol- lowed by Mbale Regional Referral Hospital (11,SD 8.3). Colorectal cancer was most common in Mbale Regional Referral Hospital (10, SD 8.1) followed by Lacor Hospital (5, SD 3.9). The differences in the mean cases load was significant for oesophageal, liver, stomach and colorectal cancers $(\mathrm{P}<0.001$, Table 2). 
Table 2: The mean (SD) per year of cancers across the hospitals

\begin{tabular}{|c|c|c|c|c|c|c|}
\hline \multirow[b]{3}{*}{ Cancer } & \multicolumn{5}{|c|}{ Hospital } & \multirow[b]{3}{*}{ P-value } \\
\hline & Jinja & Mbale & Mbarara & Soroti & Lacor & \\
\hline & & & & & & \\
\hline Small intestine & $0.1(0.3)$ & - & $0.3(0.5)$ & $0.2(0.4)$ & $0.2(0.4)$ & 0.797 \\
\hline Gall bladder & - & $0.3(0.5)$ & $0.6(0.7)$ & - & $0.3(0.5$ & 0.486 \\
\hline Billary & $0.2(0.4)$ & - & $0.8(0.6)$ & $0.1(0.3)$ & $0.3(0.5)$ & 0.532 \\
\hline Pancreatic & $0.3(0.5)$ & $1(0.8)$ & $1.7(1.8)$ & $0.1(0.3)$ & $3.1(2.2)$ & 0.768 \\
\hline Anal & $0.8(0.8)$ & $2.5(2.1)$ & $1.1(1.0)$ & $1.4(1.1)$ & $3.3(2.9)$ & 0.086 \\
\hline Colorectal & $1.6(1.9)$ & $10.3(8.1)$ & $3.2(2.6)$ & $1(0.9)$ & $4.9(3.9)$ & $<0.001$ \\
\hline Stomach & $0.1(0.3)$ & $4.1(2.5$ & $16.6(13,0$ & $0.3(0.7)$ & $5.9(5.2)$ & $<0,001$ \\
\hline Liver & $0.2(0.4$ & $11.4(8.3)$ & $4.5(4.2)$ & $0.7(1.6)$ & $21(17.7)$ & $<0.001$ \\
\hline Oesophageal & $1.8(2.5)$ & $8.4(4.8)$ & $21.8(15.5)$ & $1(1.4)$ & $9.3(9.2)$ & $<0.001$ \\
\hline
\end{tabular}

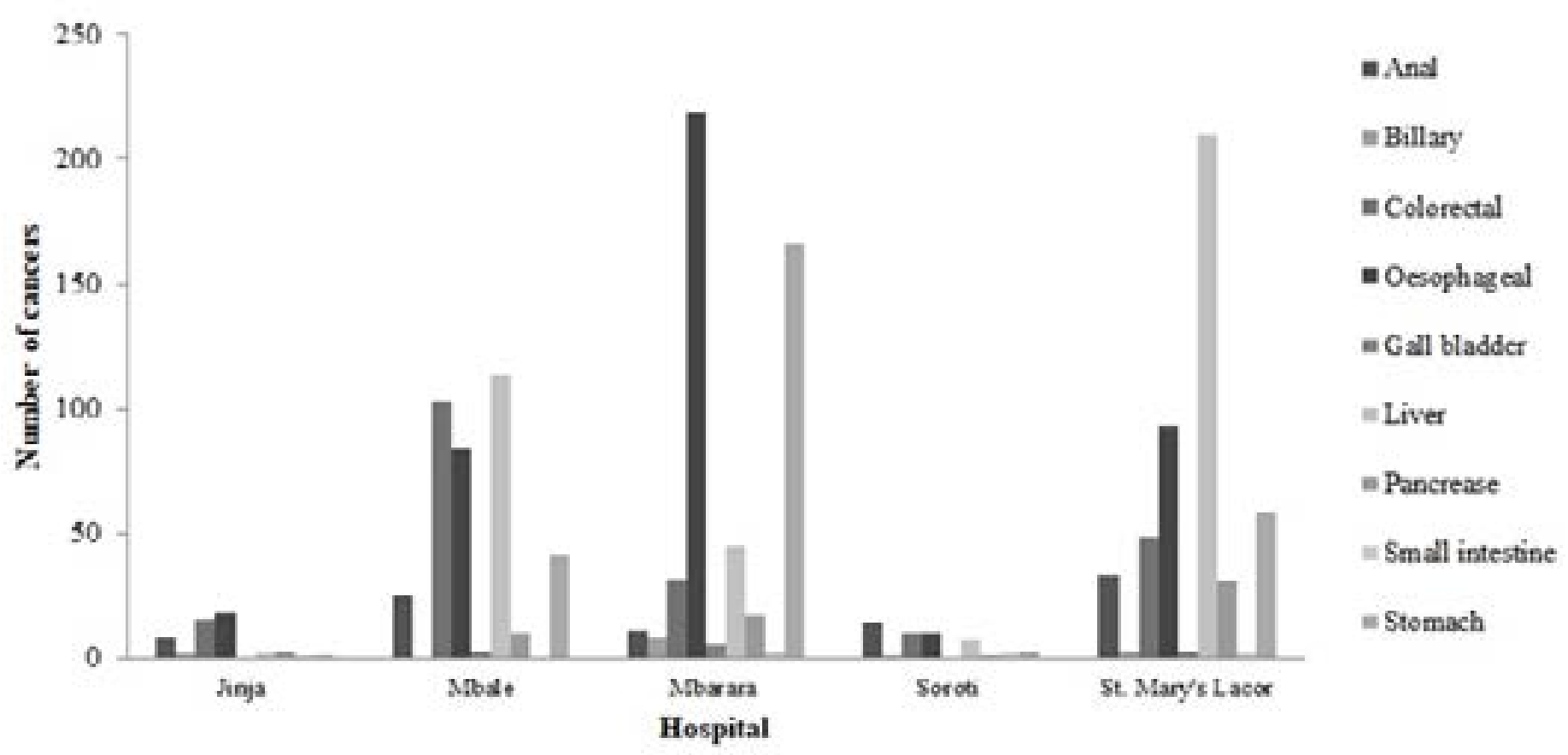

Figure 3: The number of cancer cases across the hospitals 


\section{Discussion}

One thousand four hundred and sixty eight cases of gastrointestinal cancer cases were reviewed, oesophageal cancer was the most common $(28.8 \%)$. It was most common in Mbarara University Teaching Hospital, Western Uganda with a mean of 22 cases annually. This was similar to earlier studies in Ethiopia, Tanzania and Kenya, which found that oesophageal cancer was the most common gastrointestinal malignancy in those countries. ${ }^{13-16}$ The frequency could be due to a number of factors, including an aging population as the life expectancy in Uganda is increasing. Other risk factors are tobacco use, alcohol intake, poor dietary patterns such as consumption of a maize-based diet that is low in fruits and vegetables. Contamination of maize with fungi may lead to the production of fumonisins, which are carcinogenic. ${ }^{17}$ However these modifiable factors are yet to be established in our setting.

Liver cancer was the second most common cancer, (25.7\%). This cancer appears to have become more common during the study period. St. Mary's Hospital Lacor in Northern Uganda had the highest mean number of 21 per year. This could be attributable to Hepatitis B infection which is prevalent in this region. ${ }^{18,19}$ An earlier study from urban Kampala has shown an increasing trend in liver cancer particularly in women, however the reason for this is unclear. ${ }^{20}$

Stomach (18.4\%) and colorectal cancers (14.3\%) also showed an increasing trend, similar to studies from Tanzania, Kenya, Ghana and Nigeria. ${ }^{21-25}$. The rate of stomach cancer was high with 17 cases per year. On average, in Mbarara University Teaching Hospital, Western Uganda. This could be partly related to diet and partly to precancerous lesions, particularly Helicobacter pylori related chronic gastritis that is prevalent there. ${ }^{26,27}$

Mbale Regional Referral Hospital had the highest mean number of 10 per year for colon cancer, however we could not find the reason for this in the literature. Anal cancer accounted for $6.2 \%$. Small intestinal cancers and other malignant tumours of the gastrointestinal tract including pancreatic, biliary and gall bladder cancers were uncommon, as shown in the earlier studies in Ethiopia and Kenya. ${ }^{13,28,29}$ This could be explained by limited, inadequate facilities and expertise in diagnosing pathology in some of these gastrointestinal tract sites, resulting in under reporting and documentation in these settings.

\section{Limitations}

This study has several limitations. (i) Only regional referral and teaching hospitals where involved, thus cases only seen at district hospitals may have been missed and thus case ascertainment may be incomplete. (ii) We were unable to calculate the age-specific incidence rates and incidence in this study, as there is limited population data. (iii) We cannot exclude diagnostic bias based on interest, expertise and access to diagnostic facilities.

(iv) We only considered histologically-confirmed diagnoses: gastrointestinal cancers like that of pancreas and liver that can be diagnosed with clinical features and imaging only, and those cancers whose histological reviews missed confirmation could have been missed thus under estimating their burden.

\section{Conclusion}

Oesophageal, liver, stomach and colorectal cancer remain the most common gastrointestinal malignancies in Uganda and appear to be increasing. Oesophageal and liver cancers predominate. There is a need for awareness, endoscopic and radiological assessment of symptomatic individuals as well as surveillance of pre-malignant lesions. Screening campaigns have greatly improved the outcomes for patients with colorectal cancer in Europe, stomach cancer in Japan. Vaccination programmes could reduce the transmission of hepatitis B and surveillance of those with cirrhosis used to find cancers.

Treating of H.pylori will reduce the prevalence of stomach cancer. Routine fecal screening tests to detect occult blood loss: positive fecal testing should then prompt investigation, however helminthic infections remains more common than colorectal cancer. There is plenty that can and should be done to prevent deaths from gastrointestinal cancers in Uganda.

\section{Acknowledgements}

We would like to thank the clinical and medical records staff of Mbarara University Teaching Hospital, Gulu University Teaching Hospital (St Marys' Hospital Lacor), Mbale, Jinja and Soroti Regional Referral Hospitals for their continued assistance and cooperation rendered during the study period. The research assistants who abstracted the data, Bob Lanese of Case Western Reserve University, Cleveland, Ohio, USA for setting up the data base, Seunghee Margevicius, Mark Schluchter of Case Western Reserve University Cleveland, Ohio, USA, Ron- 
ald Ssenyonga of College of Health Science, Makerere University and Nickolas Matsiko of the Joint Clinical Research Center (JCRC) Uganda, who did the data analysis.

\section{Declaration of conflicting interests}

The authors declare that there is no conflict of interest.

\section{Funding acknowledgement}

This research received no specific grant from any funding agency in the public, commercial, or not for profit sectors.

\section{References}

1. Ameqbor K, Napo-Koura GA, Redah D, Tekou A. Epidemiological and pathological gastrointestinal tumors in Togo. Gastroenterol Clin Biol. 2008; 32(4): 430-4.

2. Abdulkareem FB, Faduyile FA, Daramola AO. Malignant gastrointestinal tumours in southwestern Nigeria: a histopathologic analysis of 713 cases. West Afr J Med. 2009; 28(3): 173-6.

3. Segal I, Ally R, Mitchell H: Gastric cancer in sub-Saharan Africa. Eur J Cancer Prev 2001, 10:479-482.

4. Oluwasola AO, Ogunbiyi JO: Gastric cancer: aetiological, clinicopathological and management patterns in Nigeria. Niger J Med 2003, 12:177-186.

5. Kitinya JN, Lauren PA, Jones ME, Paljarvi L: Epidemiology of intestinal and diffuse types of gastric carcinoma in the Mount Kilimanjaro area, Tanzania. Afr J Med Med Sci 1988, 17:89-95.

6. Wabinga H, Nambooze S, Amulen P M. Trends in the incidence of cancer in Kampala, Uganda1991-2010. Int. J. Cancer 2013; 135, 432-439.

7. Hutt M S R, Burkitt D. Geographical Distribution of Cancer in East Africa: A New Clinicopathological Approach. Brit. med. Jt. 1965; 2, 719-722.

8. Bijlsma F. Gastric carcinoma in Uganda. Tropic. Geogr. Med 1974:26:1-8.

9. Cook PJ, Burkitt DP. Cancer in Africa. Br Med Bull 1971; 27:14-20.

10. Hutt MSR, Burkitt DP, Shepherd DJ. Malignant tumours of the gastrointestinal tract in Uganda. Nat Cancer Inst Monograh. 1966; 25:41-47.

11. Wabinga HR, Parkin DM, Wabwire F M, Nambooze S.Trends in cancer incidence in Kyadondo County, Ugan- da, 1960-1997. British Journal of Cancer 2000; 82(9), 15851592.

12. Wabinga HR. Pattern of cancer in Mbarara, Uganda. EAMJ 2002; 79 (4).

13. Tessema A, Orvar J, Adem A.Gastrointestinal tract cancer: a five year study in a teaching central referral hospital, Ethiopia. Ethiop Med J 2000, 38(2): 93-103.

14. Mabula D M, Peter F R, Phillipo L C. Endoscopic and clinicopathological patterns of esophageal cancer in Tanzania: experiences from two tertiary health institutions. World Journal of Surgical Oncology 2013, 11:257.

15. Wakhisi J, Kritika P, Buziba N, Rotich J. Esophgeal cancer in north rift valley of Western Kenya. African Health Sciences 2005, 5(2): 156-163.

16. Abate B, Senait A, Endale K.Patterns of gastrointestinal tumours at Atikur Anbessa Teaching Hospital in Addis Ababa, Ethiopia. Ethiop Med J 2009, 47(1).

17. Jemal A, Bray F, Forman D. Cancer burden in Africa and opportunities for prevention. Cancer 2012; 118:437284.

18. Bwogi J, Braka F, Makumbi I. Hepatitis B infection is highly endemic in Uganda: findings from a national serosurvey. Afr Health Sci 2009, 9:98-108.

19. Ochola E, Ocama p, Orach C G. High burden of hepatitis B infection in Northern Uganda: results of a population-based survey BMC Public Health 2013, 13:727. 20. Ocama P, Nambooze S, Opio CK. Trends in the incidence of primary liver cancer in Central Uganda, 19601980 and 1991-2005. Br J Cancer 2009; 100:799-802.

21. Mabula JB, Mabula D M, Koy M, Chalya P L, Massaga F, Rambau P F et al. Gastric cancer at a university teaching hospital in northwestern Tanzania: a retrospective review of 232 cases. World Journal of Surgical Oncology 2012, 10:257.

22. McFarlane G, Forman D, Sitas F and Lachlan G. Aminimum estimate for the incidence of gastric cancer in Eastern Kenya. British Journal of Cancer 2001; 85(9):

1322-1325.

23. Dakubo JC, Naaeder SB, Tettey Y, Gyasi RK. Colorectal carcinoma: an update of current trends in Accra. West Afr J Med. 2010; 29(3): 178-83.

24. Ibrahim KO, Anjorin AS, Afolayan AE, Badmos KB. Morphology of colorectal carcinoma among Nigerians: a 30-year review. Niger J Clin Pract. 2011; 14 (4): 432-5. 
25. Chalya P L, Mabula D M, Joseph B, Rambau P F, Jaka $\mathrm{H}$, Koy $\mathrm{M}$ et al. Clinicopathological patterns and challenges of management of colorectal cancer in a resource-limited setting: a Tanzanian experience. World Journal of Surgical Oncology 2013, 11:88.

26. Newton R, Ziegler JL, Casabonne D, et al. Uganda Kaposi's Sarcoma Study Group. Helicobacter pylori and cancer among adults in Uganda. Infect Agent Cancer 2006; 1:5.
27. Obayo S, Muzoora C, Ocama P, Cooney MM, Tony W, Probert CS. Upper gastrointestinal diseases in patients for endoscopy in South-Western Uganda. Afri Health Sci. 2015; 15(3): 959-66.

28. Ogutu EO. The pattern of pancreatic carcinoma at Kenyatta National Hospital. East Afr Med J 1986; 66: 105108.

29. Atoba MA, Olubuyide IO, Aghadiuno PO. Gastrointestinal malignancies in a young tropical African population. Tropical doctor 1989; 19:135-137. 